\title{
Calculation of baculovirus titer using a microfluidic-based bioanalyzer
}

\author{
Vikash Malde and Ian Hunt \\ Novartis Horsham Research Centre, Horsham, West Sussex, UK
}

BioTechniques 36:942-946 (June 2004)

Baculovirus-mediated protein expression is one of the most popular vehicles for the overproduction of recombinant proteins, which are required for the structural and functional study of therapeutically relevant biomolecules. It has many advantages including high expression levels, posttranslational modification, and the capacity to simultaneously express multiple gene products. Typically, before any largescale expression work can commence, a myriad of optimization experiments are required to ensure the most appropriate expression conditions. As part of these studies, the titer of the recombinant viral stock is determined, thereby allowing the calculation of multiplicity of infections (MOIs) and ensuring cross-referencing and reproducibility in subsequent experiments. Baculovirus titer has traditionally been calculated using plaque assay (1), end point dilution $(2)$, or immunoassay $(3,4)$ methodologies. In addition, several other strategies have been published, which include the determination of viral titer by real-time PCR (5) and a rapid antibody-based approach that allows viral titer determination in $10 \mathrm{~h}$ (6). All of these approaches have their own respective merits, however, they all share an overriding problem in that they take considerable periods of time to complete and/or can be difficult to interpret, giving rise to high variability between users. Therefore, despite the popularity of the baculovirus expression system in protein production laboratories worldwide, there is no fast, reliable, and inexpensive method of virus titer determination. We have therefore developed an automated method for the determination of baculovirus titer that uses green fluorescent protein (GFP)linked coexpression plasmids similar to those recently described (7) and the Agilent 2100 Bioanalyzer (Agilent Technologies UK Ltd., Stockport, UK) to generate quick, highly reproducible viral titer estimates.

An XhoI-KpnI flanking GFP fragment was generated by standard PCR and subcloned into the p10 multiple cloning site (MCS) of pFastBac Dual ${ }^{\mathrm{TM}}$ (Invitrogen, La Jolla, CA, USA) to create a GFP coexpression plasmid compatible with the Bac-to-Bac ${ }^{\circledR}$ Expression System (Invitrogen) $(8,9)$. GFP pFastBac Dual was transposed into DH10Bac ${ }^{\mathrm{TM}}$ competent cells (both from Invitrogen), and recombinant bacmid was isolated following the manufacturer's instructions. Bacmid was then transfected into $S f 21$ cells, and high titer recombinant virus was produced. Viral titer was calculated using a standard viral plaque assay (1), the BacPAK ${ }^{\mathrm{TM}}$ immunoassay kit (BD Biosciences, San Jose, CA, USA) or the Agilent 2100 Bioanalyzer, following the manufacturer's instructions or as described in the figure legends.

In an initial experiment to ascertain whether recombinant baculovirus-expressing GFP could be detected using the Agilent 2100 Bioanalyzer, we infected a $50-\mathrm{mL}$ culture of $S f 21$ cells with $1 \mathrm{~mL}$ of GFP virus. Following incubation for $48 \mathrm{~h}$ at $27^{\circ} \mathrm{C}$, the cells were harvested, stained with the live cell dye carboxynaphthofluorescein diacetate (CBNF; Molecular Probes, Eugene, OR, USA), and analyzed using the Agilent 2100 Bioanalyzer. Figure 1 shows frequency histograms of live (CBNF-positive) and GFP-expressing $S f 21$ cells that have been infected with a $1 \mathrm{~mL}$ volume of $10^{-1}$ diluted GFP viral stock. To determine the percentage of GFP-expressing cells, live cells in the CBNF-positive population were simply cross-gated onto the GFP histogram. Figure 1 shows that $13.3 \%$ of live CBNF cells can be cross-gated with GFP fluorescence. Determining the number of CBNF-positive cells and the number of GFP-expressing cells also allows the calculation of the viral titer using the equation described by Berns and Giraud (10). Viral titer (IU/ $\mathrm{mL}$ ) can be calculated from the number of GFP-expressing cells divided by the volume of virus added, multiplied by the number of CBNF-labeled cells, and corrected for dilution.

The calculated value is $1.29 \times 10^{6}$ $\mathrm{IU} / \mathrm{mL}$ and compares favorably with the viral titer calculated using the traditional plaque assay $\left[4.1 \times 10^{6}\right.$ plaque-forming units $(\mathrm{pfu}) / \mathrm{mL}]$ or the BacPAK immunoassay $\left(6.4 \times 10^{6} \mathrm{IU} /\right.$ $\mathrm{mL})$. It is noteworthy that since $S f 21$ cells are maintained in suspension culture throughout the course of the experiment (and are not immobilized as is the case in plaque and immunological methodologies), there is a chance that secondary infections may occur, thereby giving rise to overestimates of viral titers. However, based on the estimates given above, the method derived in this paper appears to provide a value that is actually slightly lower than the other approaches. This suggests that such concerns are not a major issue, although further study is required before a definitive conclusion can be drawn. In a separate experiment, we also tested the sensitivity of the method. Table 1 shows that after $48 \mathrm{~h}$, the number of GFP-gated events in $S f 21$ cells infected with GFP-containing baculovirus drops from 86 (9.8\% gated) to 4 (1.4\% gated) when the virus added is diluted from $10^{-1}$ through to $10^{-3}$. Conversely, Sf 21 cells when infected with the GFP-minus baculovirus consistently show only 3-4 GFP-gated events $(0.5 \%-1 \%$ gated). This small number of events presumably represents background fluorescence because no GFP is present in any of these samples. Taken together, this suggests that the GFP-containing virus is effectively removed from the cells by dilutions at $10^{-3}$ and beyond. However, it must be stressed that for each recombinant virus studied, the point at which the virus is effectively neutralized by dilution will vary considerably. For example, in the case of a stock with 
Table 1. Sensitivity of Detection of GFP and Non-GFP-Containing Baculovirus Measured Using the Agilent 2100 Bioanalyzer

\begin{tabular}{|c|c|c|c|c|c|}
\hline Flask & Dilution & $\begin{array}{l}\text { Total Events } \\
\text { (No.) }\end{array}$ & $\begin{array}{l}\text { CBNF Events } \\
\text { (No.) }\end{array}$ & $\begin{array}{l}\text { GFP Events } \\
\text { (No.) }\end{array}$ & $\begin{array}{c}\text { Gated } \\
(\%)\end{array}$ \\
\hline \multicolumn{6}{|c|}{ GFP-Infected Cells } \\
\hline 1 & $10^{-1}$ & 965 & 879 & 86 & 9.8 \\
\hline 2 & $10^{-2}$ & 708 & 633 & 9 & 1.4 \\
\hline 3 & $10^{-3}$ & 747 & 654 & 4 & 0.6 \\
\hline 4 & $10^{-4}$ & 802 & 598 & 5 & 0.8 \\
\hline 5 & $10^{-5}$ & 751 & 518 & 3 & 0.6 \\
\hline 6 & $10^{-6}$ & 762 & 478 & 4 & 0.8 \\
\hline \multicolumn{6}{|c|}{ Mock-Infected Cells } \\
\hline 1 & $10^{-1}$ & 934 & 913 & 3 & 0.3 \\
\hline 2 & $10^{-2}$ & 833 & 802 & 4 & 0.5 \\
\hline 3 & $10^{-3}$ & 789 & 754 & 5 & 0.6 \\
\hline 4 & $10^{-4}$ & 694 & 613 & 3 & 0.5 \\
\hline 5 & $10^{-5}$ & 716 & 624 & 3 & 0.5 \\
\hline 6 & $10^{-6}$ & 656 & 574 & 5 & 0.9 \\
\hline \multicolumn{6}{|c|}{$\begin{array}{l}\text { Sf21 cells }\left(6 \times 50 \mathrm{~mL} \text { volumes; } 0.5 \times 10^{6} \text { cells } / \mathrm{mL} \text { ) were infected with a } 1-\mathrm{mL} \text { volume of viral stock (GFP- }\right. \\
\text { expressing and non-GFP-expressing) diluted to } 10^{-1}, 10^{-2}, 10^{-3}, 10^{-4}, 10^{-5} \text {, and } 10^{-6} \text { and incubated for } 48 \\
\mathrm{~h} \text { at } 27^{\circ} \mathrm{C} \text {. The cells were then harvested, and samples were prepared for analysis as described in the } \\
\text { Figure } 1 \text { legend. Prior to dilution, the titers of both GFP-minus and GFP-containing baculovirus stocks } \\
\text { were determined by plaque assay and normalized to } 0.64 \times 10^{7} \text { plaque-forming units (pfu) } / \mathrm{mL} \text { by dilution. } \\
\text { GFP, green fluorescent protein; CBNF, carboxynaphthofluorescein diacetate. }\end{array}$} \\
\hline
\end{tabular}

a viral titer of $10^{8} / \mathrm{mL}$, the use of a $10^{-1}$ dilution to calculate titer could cause significant secondary infections, giving rise to erroneous results. We therefore recommend that a serial dilution profile

is performed on each viral stock to ascertain the most appropriate conditions for the calculation of viral titer when using this method. Finally, to ascertain the reproducibility of the assay and to identify any variability between cell fluorescence LabChips ${ }^{\circledR}$ (Cell Fluorescence LabChip Kit; Agilent Technologies UK Ltd.), we infected four flasks with GFP and analyzed them on multiple chips. Figure 2 shows that for each flask infected with GFP-containing baculovirus, the number of total cell events, the number of live CBNF events, and the number of GFP-gated events calculated are in extremely close agreement. Similarly, this pattern is also observed between different chips, suggesting the high reproducibility of the system.

In summary, we report the development of a fast and highly reproducible method of calculating the viral titer of a baculovirus stock using the Agilent 2100 Bioanalyzer and the Cell Fluorescence LabChip Kit in concert with GFP baculovirus coexpression plasmids. The method here offers several advantages over alternative approaches for viral titer calculation. First, because data collection is automated by the $\mathrm{Ag}$ ilent 2100 Bioanalyzer, it does not rely on the operator to differentiate between infected and noninfected cells. Automation of data collection removes user-to-user variability, one of the largest sources of error associated with other viral titer determination methods. Second, the method is very quick and simple to perform. Forty-eight hours postinfection, insect cells infected with GFP-containing virus can be harvested, and within $90 \mathrm{~min}$, a value for viral titer can be determined. This compares favorably with the more timeconsuming and laborintensive plaque assay and immunoassay, which both require an extensive washing and fixing of cells.

While at first glance this strategy requires the use of an expensive machine
Figure 1. GFP-infected $S f 21$ cells analyzed by the Agilent 2100 Bioanalyzer. Cell culture volumes of $50 \mathrm{~mL}\left(0.5 \times 10^{6}\right.$ cells $/ \mathrm{mL}$ ) were infected with $1 \mathrm{~mL}$ of GFP virus and incubated for $48 \mathrm{~h}$ at $90 \mathrm{rpm}$ at $27^{\circ} \mathrm{C}$. Following incubation, the cells were counted, harvested, and resuspended at $1 \times 10^{6}$ cells $/ \mathrm{mL}$ in HEPES-buffered saline solution (HBSS) with $0.05 \%(\mathrm{v} / \mathrm{v}$ ) pluronic acid (Molecular Probes). The cells were then stained for $15 \mathrm{~min}$ at room temperature with $0.5 \mu \mathrm{M}$ of the live cell dye carboxynaphthofluorescin diacetate (CBNF), pelleted by centrifugation at $500 \times g$ for $5 \mathrm{~min}$, and resuspended in cell buffer $(2 \times$ $10^{6}$ cells $/ \mathrm{mL}$ ). Ten microliters of viral sample were then loaded onto a cell fluorescence LabChip and analyzed on the Agilent 2100 Bioanalyzer (11). GFP, green fluorescent protein; N.A., not applicable. 


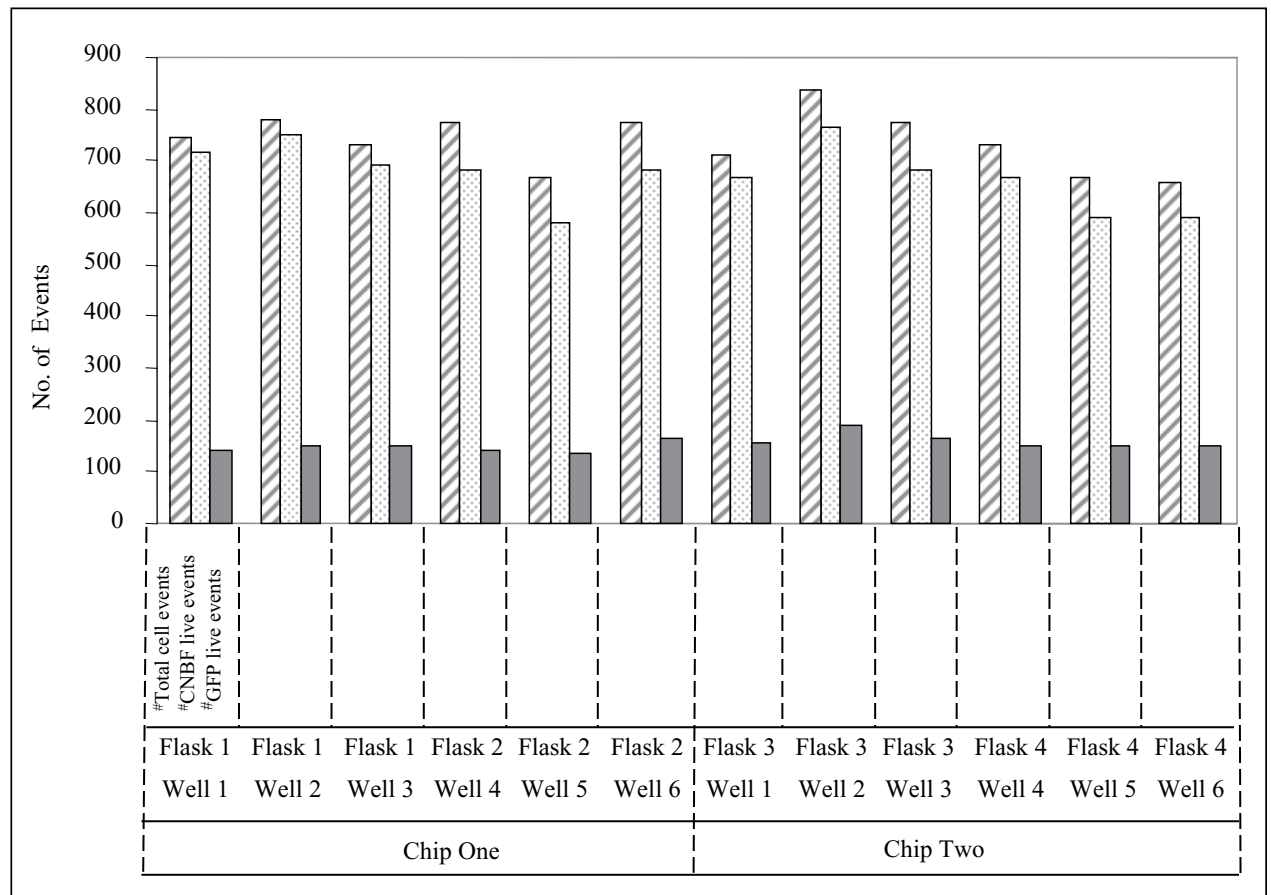

Figure 2. Reproducibility of baculovirus infection using the Agilent 2100 Bioanalyzer. $S f 21$ cells $(4 \times 50 \mathrm{~mL}$ volumes; $0.5 \times 10^{6}$ cells $/ \mathrm{mL}$ ) were infected with $1 \mathrm{~mL}$ of viral stock that was diluted $10^{-1}$. Following incubation for $48 \mathrm{~h}$ at $27^{\circ} \mathrm{C}$, the cells were harvested, and samples were prepared for analysis as described in Figure 1. For each 50-mL Sf21 flask infected with green fluorescent protein (GFP)-containing virus, samples were prepared and loaded in triplicate onto a single cell fluorescence chip for data capture. Two chips were analyzed, each containing two flasks loaded in triplicate and total (\#Total cell events), CBNF dye-labeled (\#CBNF live events), and GFPexpressing (\#GFP live events) cell numbers were determined for each well and plotted. CBNF, carboxynaphthofluorescein diacetate. (the Agilent 2100 Bioanalyzer), the protocol could also be used in concert with other flow cytometry systems [fluorescence-activated cell sorter (FACS ${ }^{\circledR}$; BD Biosciences) or $\mathrm{MoFlo}^{\circledR}$ (DakoCytomation, Carpinteria, CA, USA)], thus making this approach widely applicable to many laboratories. It is also noteworthy that this strategy could be adapted for use on adherent insect cell cultures. Using standard 6well plates, cells could be infected with viral stock and, following incubation, simply detach from the plate and resuspend, ready for analysis using standard techniques. Indeed, this approach may be more favorable in many laboratories where suspension cultures are not typical. A second approach would be the use of 24-deep-well blocks for the culture of insect cells and concomitant infection with virus. Both of these approaches have the advantage of requiring much smaller volumes of cells and virus.

To further facilitate baculovirus- mediated expression using this system, we have adapted the GFP coexpression plasmid described above to make use of GATEWAYTM technology (Invitrogen). Thus, the use of the GATEWAY rapid cloning, in conjunction with the enhanced speed and reproducibility of the Agilent viral titer method described here, has enabled us to make significant savings in time and effort in our protein optimization studies.

\section{ACKNOWLEDGMENTS}

The authors wish to thanks Daljit Bahia and Ruth Finch (Agilent Technologies) for useful discussions and comments during the preparation of this manuscript.

\section{REFERENCES}

1.Hink, W.F. and P.V. Vail. 1973. A plaque assay for titration of alfalfa looper nuclear polyhedrosis virus in a cabbage looper TN-368 cell line. J. Invertebr. Pathol. 22:168-174. 2.O'Reilly, D.R., L.K. Miller, and V.A. Luckow. 1992. Virus methods, p. 132. Baculovirus Expression Vectors: A Laboratory Manual. WH Freeman \& Co., New York.

3.Volkman, L.E. and P.A. Goldsmith. 1981. Baculovirus bioassay not dependent upon polyhedra production. J. Gen. Virol. 56:203-206.

4.Kitts, P.A. and R.D. Possee. 1993. A method for producing recombinant baculovirus expression vectors at high frequency. BioTechniques 14:810-817.

5.Lo, H.-R. and Y.-C. Chao. 2004. Rapid titer determination of baculovirus by quantitative real-time polymerase chain reaction. Biotechnol. Prog. 20:343-360.

6.Kwon, M.S., T. Dojima, M. Toriyama, and E.Y. Park. 2002. Development of an antibody-based assay for determination of baculovirus titers in 10 hours. Biotechnol. Prog. 18:647-651.

7.Philipps, B., M. Forstner, and L.M. Mayr. 2004. Baculovirus expression system for magnetic sorting of infected cells and enhanced titer determination. BioTechniques 36:80-83.

8.Eriksson, S., E. Ravioli, J.P. Kikkoman, K. Eriksson, and C. Lindquist. 1996. Green fluorescent protein as a tool for screening recombinant baculovirus. J. Virol. Methods 59:127-133.

9.Cha, H.J., T. Gotoh, and W.E. Bentley. 1997. Simplification of titer determination for recombinant baculovirus by GFP markers. BioTechniques 23:782-786.

10.Amiss, T.J. and R.J. Samulski. 2001. Methods for Adeno-Associated

Virus-Mediated Gene Transfer into Muscle. Methods in Molecular Biology, vol. 175: Genomics Protocols, Chapter 27. Humana Press, Totowa, NJ.

11.Hahnenberger, K. and S. Chan. 2000. Monitoring transfection efficiency by green florescent protein (GFP) detection with the Agilent 2100 Bioanalyser. Application Note, Agilent Technologies UK Ltd., Stockport, UK

Received 22 January 2004; accepted 12 March 2004

Address correspondence to Ian Hunt, Novartis Horsham Research Centre, Novartis Institutes for Biomedical Research, Wimblehurst Road, Horsham, West Sussex, RH12 5AB,UK.e-mail: ian-1.hunt@pharma. novartis.com 